\title{
UCLA
}

\section{Recent Work}

Title

Motivating entrepreneurial activity in a firm

Permalink

https://escholarship.org/uc/item/9x19j2if

\section{Authors}

Bernardo, Antonio E.

Cai, Hongbin B

Luo, Jiang

Publication Date

2005-07-28 


\title{
Motivating entrepreneurial activity in a firm*
}

\author{
Antonio E. Bernardo ${ }^{\dagger}$ \\ Hongbin Cai ${ }^{\ddagger}$ \\ Jiang $\mathrm{Luo}^{\S}$
}

July 2005

\begin{abstract}
We consider the problem of motivating privately informed managers to engage in entrepreneurial activity to improve the quality of the firm's investment opportunities. The firm's investment and compensation policy must balance the manager's incentives to provide entrepreneurial effort and to report her private information truthfully. The optimal policy is to underinvest (compared to first-best) and provide weak incentive pay in low-quality projects and overinvest (compared to first-best) and provide strong incentive pay in high-quality projects. We also show that, unlike the standard agency model, uncertainty and incentives can be positively related.
\end{abstract}

${ }^{*}$ We thank seminar participants at the University of Illinois at Urbana-Champaign, Stanford, and UC, San Diego for helpful comments. All errors are ours.

${ }^{\dagger}$ Corresponding author: UCLA Anderson School, 110 Westwood Plaza Box 951481, Los Angeles, CA 90095-1481, USA. e-mail: abernard@anderson.ucla.edu

${ }^{\ddagger}$ Department of Economics, UCLA, Los Angeles, CA 90095-1477, USA

$\S$ Department of Finance, HKUST, Clear Water Bay, Hong Kong 


\section{Introduction}

Fostering entrepreneurial activity within a firm is critical to its success, especially in highgrowth industries. Many observers have argued, for example, that in rapidly changing industries large, established firms are at a disadvantage to small, young firms because of structural and informational impediments to entrepreneurial activity such as slow-moving and bureaucratic organizations (Henderson, 1993), an over-reliance on the needs of existing clients (Christensen, 1997), internal rent-seeking behavior which leads to a "socialistic" allocation of capital across divisions (Rajan, Servaes, and Zingales, 2000), and difficulties assessing the quality of growth opportunities outside their core business (e.g., Stein, 1997; Scharfstein and Stein, 2000). In this paper, we argue that a firm must tap its workers' abilities to improve and expand its growth opportunities (i.e., "entrepreneurial effort"). For example, engineers can expend effort to develop new products or division managers can search for new markets. One way to encourage such privately costly activity in a firm is to link pay to investment performance. ${ }^{1}$ But unless workers believe that the firm will aggressively pursue new opportunities they will recognize that their entrepreneurial activity will be wasted and may decide to take their ideas elsewhere. ${ }^{2}$

We examine these issues by considering a firm that wishes to motivate a manager to improve its investment opportunities. The manager's "entrepreneurial effort" can be interpreted as any activity that enhances the average quality of investments available to the firm or improves the expected performance of a given investment prior to its funding (e.g., product innovation). We assume that in the process of expending entrepreneurial

\footnotetext{
${ }^{1}$ This may also help to attract creative, risk-taking individuals to the firm, however, we do not formally model this selection process (see, e.g., Jovanovic, 1979)

${ }^{2}$ The classic example of this is Xerox whose executives resisted the commercialization of numerous valuable technologies, such as the ethernet and the graphical user interface, developed at their Palo Alto Research Center. Most of the value from these technologies was captured by workers who left Xerox to start new companies. Gompers, Lerner and Scharfstein (2005) provide a detailed empirical analysis of the forces leading to "entrepreneurial spawning" in firms.
} 
effort the manager learns private information unknown to the firm. The firm must decide how much to invest in the project based on a report of its quality prepared by the manager. Once the investment is made, the manager can also enhance the value of the project by exerting "managerial effort" representing activities that can enhance project performance after it is funded. The manager's entrepreneurial and managerial efforts are both assumed to be non-verifiable, non-contractible, and privately costly.

The firm's investment and compensation policy must balance the manager's incentives to provide appropriate effort, entrepreneurial and managerial, and to report her private information truthfully. In particular, funding all internal ventures aggressively motivates appropriate effort but also encourages managers to overstate project quality in order to garner more funding. We show that the firm's optimal policy is to underinvest and provide low-powered incentives (relative to first-best) in low-quality projects and overinvest and provide high-powered incentives (relative to first-best) in high-quality projects. The compensation policy encourages truthful reporting by making the manager's pay more dependent on the project's performance when she reports that it is higher quality. Interestingly, the firm need not commit to invest in all new ventures to motivate entrepreneurial activity; instead, it must commit to heavily fund only the best projects. We show that the overinvestment result depends critically on the firm's need to motivate entrepreneurial activity, i.e., in the absence of entrepreneurial effort the firm always underinvests. ${ }^{3}$

We provide a number of novel cross-sectional predictions about entrepreneurial activity, the funding of internal ventures, and managerial compensation. For example, we argue that aggressive funding and strong performance incentives are more desirable for young, high-growth firms and diversified firms. Since workers expect high rents from working in these firms, they are less likely to leave their firms and take their ideas elsewhere. These predictions are consistent with the empirical evidence that young, high-growth firms and

\footnotetext{
${ }^{3}$ Bernardo, Cai, and Luo (2001) consider a similar problem but without entrepreneurial effort and find that the firm optimally underinvests in all projects.
} 
diversified firms are less likely to "spawn" new venture capital backed startups (Gompers, Lerner and Scharfstein, 2005). Moreover, uncertainty and performance incentives can be either positively or negatively related depending on parameters. ${ }^{4}$ In the standard model, uncertainty and incentives are negatively related because uncertainty increases the cost of incentive provision (since the manager is risk-averse) but does not impact the benefit of incentive provision (since effort simply shifts the project payoff by a constant amount). ${ }^{5}$ In our model, however, the cost of incentive provision increases in uncertainty but so does the benefit of motivating entrepreneurial effort because it increases the value of the firm's option to fund good investment opportunities and avoid bad investment opportunities. We show that the marginal cost of increasing incentive provision is relatively low for high-quality projects and find that uncertainty and incentives are positively related for sufficiently high-quality projects. ${ }^{6}$

There is a growing literature analyzing the factors that determine whether entrepreneurs raise venture capital funding (e.g., Hellmann and Puri, 2000; Gromb and Scharfstein, 2005) and the factors that affect the terms of this financing (e.g., Gompers, 1995; Hellmann, 1998; Kaplan and Strömberg, 2003), but there is much less understanding of how established firms develop and finance internal ventures. We try to fill this gap. Our paper is also related to the literature examining the role of incentives in the capital budgeting process when there is asymmetric information and/or managerial moral hazard (see, e.g., Antle and Eppen, 1985; Harris and Raviv, 1996; Bernardo, Cai, and Luo, 2001). In comparison, the novel feature of our model is that the manager can impact the investment

\footnotetext{
${ }^{4}$ Prendergast (2002) surveys empirical evidence finding both a positive and negative relation.

${ }^{5}$ See, e.g., Holmstrom, 1979; Rosen, 1982; Holmstrom and Milgrom, 1987.

${ }^{6}$ Prendergast (2002) shows that uncertainty and incentive can be positively related in a model in which firms delegate more authority to managers in uncertain environments but constrain managerial discretion by linking pay to performance. Shi (2003) proposes a learning model in which the agent's effort to collect information about the underlying state is more valuable in a more uncertain environment.
} 
opportunity set. ${ }^{7}$ Finally, our modeling approach has some similarities with Lewis and Sappington (1997), who analyze a procurement model in which an agent endogenously chooses to learn a project cost parameter. They show that to optimally motivate information acquisition, the agent is provided with "super-high-powered" contracts. In our model, information about project quality is costless to the manager, but she exerts effort to expand the investment opportunity set. To motivate such entrepreneurial effort, the headquarters not only uses excessive pay for performance but also commits to overinvest in highly promising projects.

The remainder of this paper is organized as follows. Section II presents our model. Section III derives the first-best solution as a benchmark and Section IV derives the secondbest optimal mechanism, compares the first-best and second-best outcomes, and discusses the important features and empirical implications of the second-best mechanism. We also examines the robustness of our results to more general distributions of project quality. Section V concludes.

\section{The model}

We consider a risk-neutral firm wishing to invest in a single investment project. The firm can hire a risk-neutral manager to expend entrepreneurial effort, $z \geq 0$, to improve the average quality of projects in the investment opportunity set. For example, one aspect of the manager's job description may be to engage in product innovation or make improvements to existing products. Specifically, we assume that the firm selects a single project with quality, denoted $t$, drawn from a normal distribution with mean $z$ and variance $\sigma^{2}$,

\footnotetext{
${ }^{7}$ An interesting exception is Berkovitch and Israel (2004) in which managers costlessly learn about a fixed set of projects but can choose which projects to propose to the firm. They show that a ratio-based investment criterion such as the IRR can be more efficient than the NPV criterion. They do not consider managerial moral hazard nor do they fully characterize the firm's optimal investment policy and incentive contracts.
} 
i.e., $t \sim N\left(z, \sigma^{2}\right){ }^{8}$ In this specification, entrepreneurial effort increases the average quality of the firm's investment opportunity set but does not affect its dispersion, $\sigma$.

We assume the manager knows the quality of the selected project, $t$, precisely but the firm does not observe the project quality and must decide how much capital to allocate based on the manager's report of project quality, denoted $\hat{t}$. Once the project is funded, the manager can also enhance its cash flows by exerting managerial effort, $x \geq 0$. The key distinction between entrepreneurial effort and managerial effort is that the latter represents activities undertaken after project funding. The entrepreneurial effort, $z$, and managerial effort, $x$, are assumed to be privately costly; specifically, we assume that the manager's private cost of entrepreneurial effort is given by $g(z) \equiv 0.5 \gamma z^{2}$, and the private cost of managerial effort is given by $g(x) \equiv 0.5 \gamma x^{2}$, where $\gamma>0$ is the manager's effort-aversion parameter. We assume that the manager can leave the firm at any time and obtain the reservation utility, $\bar{U}$, from outside opportunities.

The selected project generates cash flows according to:

$$
V=(\delta t+\theta x) k-0.5 k^{2}+\epsilon
$$

In this specification, $k \geq 0$ is the capital allocated by the firm, $x \geq 0$ is the manager's managerial effort, and $\epsilon$ is a mean-zero random variable (capturing measurement error). The parameters $\delta>0$ and $\theta>0$ measure the importance of project quality and the manager's managerial effort to project cash flows, respectively. The cash flow specification, $V$, has many intuitive features; for example, the marginal product of capital is increasing in project quality and the level of managerial effort. Since everyone is risk-neutral in our model, the mean zero noise term and its distribution have no effect on our results but are introduced to demonstrate their generality (Laffont and Tirole, 1986).

We assume that the firm can use two instruments, the manager's compensation package and a capital allocation rule, to provide incentives for the manager to exert appropriate

\footnotetext{
${ }^{8}$ Szalay (2003) uses a similar modeling device in the context of a procurement problem where the agent's effort can determine the distribution of types.
} 
entrepreneurial and managerial efforts and to report truthfully about project quality. The firm's problem is then to maximize expected project cash flows net of compensation costs by choosing managerial compensation, $w(\hat{t}, V)$, depending on both the report about project quality $\hat{t}$ and the cash flows $V$, and a capital allocation rule, $k(\hat{t})$, depending on the reported quality. Importantly, we assume that the project quality $t$ is unobservable and non-verifiable by the firm ex post; therefore, contracts cannot be written on $t$ directly. Moreover, the manager's entrepreneurial and managerial efforts are assumed to be unobservable and non-verifiable by the firm; therefore, the contracts cannot be written on $z$ or $x$.

To summarize, the sequence of moves of the game is as follows:

date 0: The firm offers the manager a compensation package and capital allocation rule $\{w(\hat{t}, V), k(\hat{t})\}$. The manager chooses whether or not to accept the contract.

date 1: If she accepts the contract, the manager expends entrepreneurial effort, $z$, and observes $t$ from $N\left(z, \sigma^{2}\right)$.

date 2: After observing $t$, the manager again chooses whether or not to accept the contract. If she accepts, she reports project quality $\hat{t}$.

date 3: The firm allocates capital of $k(\hat{t})$ and the manager chooses managerial effort $x$.

date 4: The project cash flows are realized and distributed to shareholders less the compensation, $w(\hat{t}, V)$, paid to the manager.

As is standard in revelation games, we assume that the firm can commit to the capital allocation rule offered to the manager at date 0 ; otherwise, the firm would optimally choose a capital allocation at date 3 that is different than the capital promised, $k(\hat{t})$, at date 0 . If, however, the manager knew this, she would not report truthfully at date 2. One natural argument in defense of this assumption is that the firm's commitment is the result of (unmodeled) reputational concerns when it must play this investment game often in the 
future. ${ }^{9}$ Finally, note that we make the important assumption that the manager can reject the contract offered at date 2 after observing the project quality. This assumption ensures the sub-optimality of selling the firm to the risk-neutral manager at date $0 .{ }^{10}$

\section{First-best solution}

Before we proceed, we make the following parameter assumptions:

(A1) $\gamma>\left(\delta^{2}+\theta^{2}\right)\left(1+\frac{\delta^{2}}{\theta^{2}}\right)$

(A2) $1.5 \theta^{2}>\gamma$.

Assumption (A1) requires that the marginal cost of the manager's efforts is increasing relatively fast compared to its marginal benefit so that the objective function of the optimal mechanism design program is concave. Assumption (A2) requires that managerial effort is sufficiently important to the productivity of capital so that entrepreneurial effort is positive in the optimal mechanism.

Let $\Phi(\cdot)$ and $\phi(\cdot)$ denote the c.d.f. and p.d.f., respectively, of the standard normal distribution and $\mu(\cdot) \equiv(1-\Phi(\cdot)) / \phi(\cdot)$ denote the inverse of its hazard rate. Below we shall use two important properties of the standard normal distribution: $\mu^{\prime}<0$ and $\mu^{\prime \prime}>0$.

\footnotetext{
${ }^{9}$ This argument also suggests that our model better describes the development and funding of internal ventures rather than venture capital financing because an established firm must deal with its managers repeatedly and thus has a stronger incentive to build a reputation for honoring its commitments.

${ }^{10}$ Without this assumption, if the headquarters (and other parts of the firm) is dispensable and the manager is not constrained by liquidity at date 0 , then indeed a sell-out contract achieves the first best. Implicitly we assume that this is not feasible, i.e., even if the headquarters can sign a contract to sell the firm to the manager at date 0 , the execution of the contract can only happen after date 2 , at which point the manager may renege on the terms for low $t$.
} 
The first-best solution maximizes the expected total surplus:

$$
\begin{aligned}
\max _{z, x(t), k(t) \geq 0} & \int_{-\infty}^{\infty}\left[E_{\epsilon} V-0.5 \gamma x^{2}\right] d \Phi\left(\frac{t-z}{\sigma}\right)-0.5 \gamma z^{2} \\
= & \int_{-\infty}^{\infty}\left[(\delta t+\theta x) k-0.5 k^{2}-0.5 \gamma x^{2}\right] d \Phi\left(\frac{t-z}{\sigma}\right)-0.5 \gamma z^{2} .
\end{aligned}
$$

Proposition 1. The first-best entrepreneurial effort can be expressed as $z^{f b}=\sigma z_{n}^{f b}$ where $z_{n}^{f b}$ is determined by:

$$
0=\frac{\delta^{2}}{\gamma}\left[\phi\left(z_{n}^{f b}\right)+z_{n}^{f b} \Phi\left(z_{n}^{f b}\right)\right]-\left(1-\frac{\theta^{2}}{\gamma}\right) z_{n}^{f b} .
$$

The first-best managerial effort and capital allocation are given by:

$$
\begin{aligned}
x^{f b}(t) & =\frac{\theta \delta}{\gamma-\theta^{2}} \max (0, t), \\
k^{f b}(t) & =\frac{\gamma \delta}{\gamma-\theta^{2}} \max (0, t) .
\end{aligned}
$$

The first-best capital allocation, $k^{f b}(t)$, and managerial effort, $x^{f b}(t)$, increase in $t$ (project quality), $\delta$ (the importance of project quality) and $\theta$ (the importance of managerial effort), and decrease in $\gamma$ (effort-aversion).

The first-best entrepreneurial effort, $z^{f b}$, increases in $\sigma$ (the dispersion of potential project qualities), $\delta$ (the importance of project quality) and $\theta$ (the importance of managerial effort), and decreases in $\gamma$ (cost of effort).

Proof: See the Appendix.

In the first-best outcome, the marginal product of capital increases in $t$ and $\delta$ (for $t>0$ ), therefore, the first-best capital allocations increase in $t$ and $\delta$. This implies that the first-best managerial effort also increases in $t$ and $\delta$ since capital and managerial effort are complementary. Conversely, the marginal benefit (cost) of managerial effort increases in $\theta(\gamma)$, therefore, the first-best managerial effort and capital allocation (due to complementarities) increase (decrease) in $\theta(\gamma)$.

While increases in $\delta$ and $\theta$ and a decrease in $\gamma$ improve the marginal product of capital and managerial effort and thus the payoff of high-quality projects $(t>0)$, the firm always 
has the option not to invest when project quality is low $(t \leq 0)$. Overall, an increase in $\delta$ and $\theta$ and a decrease in $\gamma$ improve the payoff of an average project or, equivalently, the payoff to increasing entrepreneurial effort; therefore, the first-best entrepreneurial effort increases (decreases) in $\delta$ and $\theta(\gamma)$.

Finally, entrepreneurial effort is more valuable when the uncertainty parameter $\sigma$ increases because it increases the value of the firm's option to fund good investment opportunities and avoid bad investment opportunities; therefore, the first-best entrepreneurial effort increases in $\sigma$.

\section{Optimal second-best allocation}

We now consider the firm's optimization problem when the manager's efforts and information are unobservable and non-contractible. By the Revelation Principle we can, without loss of generality, restrict our attention to direct revelation mechanisms in which the manager reports the project quality truthfully. Let $U(t, \hat{t}, x) \equiv E_{\epsilon} w(\hat{t}, V)-0.5 \gamma x^{2}$ denote the expected utility (expectation over $\epsilon$ ) of the manager when she observes $t$, reports $\hat{t}$, and exerts managerial effort $x$ (this assumes that the disutility of entrepreneurial effort is sunk). We can write the firm's optimization problem as follows:

$$
\max _{z, w(t, V), x(t), k(t)} E \Pi \equiv \int_{-\infty}^{\infty} E_{\epsilon}(V-w) d \Phi\left(\frac{t-z}{\sigma}\right)
$$

subject to

(i) $x(t, \hat{t}) \in \arg \max _{x} U(t, \hat{t}, x)$

(ii) $t \in \arg \max _{\hat{t}} U(t, \hat{t}, x(t, \hat{t}))$,

(iii) $z \in \arg \max _{\hat{z}} \int_{-\infty}^{\infty} U(t, t, x(t, t)) d \Phi\left(\frac{t-\hat{z}}{\sigma}\right)-0.5 \gamma \hat{z}^{2}$,

(iv) $U(t, t, x(t, t)) \geq \bar{U}, \forall t$,

(v) $z, x(t), k(t) \geq 0$. 
The first incentive compatibility constraint (IC1) states that the manager chooses the level of managerial effort optimally given the true project quality and her report about project quality. The second incentive compatibility constraint (IC2) restricts our attention to direct revelation mechanisms in which it is optimal for the manager to tell the truth about project quality. The third incentive compatibility constraint (IC3) states that the manager chooses entrepreneurial effort to maximize her net expected payoff, which equals her expected payoff from playing the direct revelation mechanism minus the disutility of entrepreneurial effort. The individual rationality constraint (IR) requires that after knowing the realization of project quality at date 1 , the manager must achieve expected utility at least as high as her outside option by playing the direct revelation mechanism (entrepreneurial effort cost is already sunk at this stage of the game hence it does not affect her participation decision at this time). ${ }^{11}$ The non-negativity constraint (NN) requires that entrepreneurial and managerial efforts and capital allocation are non-negative. Note that here we employ the notation $x(t) \equiv x(t, t)$ for simplicity.

For our main proposition, we must consider the following equation system:

$$
\begin{aligned}
\lambda_{n}^{*} & =\frac{\delta^{2}}{\gamma}\left[\phi\left(z_{n}^{*}\right)+z_{n}^{*} \Phi\left(z_{n}^{*}\right)\right]+\frac{\theta^{2}}{\gamma} z_{n}^{*}, \\
t_{n}^{*} & =\frac{\gamma}{\theta^{2}}\left[\mu\left(t_{n}^{*}-z_{n}^{*}\right)-\lambda_{n}^{*}\right], \\
z_{n}^{*} & =\frac{\delta^{2}}{\theta^{2}}\left[\frac{\gamma}{\gamma-\theta^{2}}\left(t_{n}^{*}+\lambda_{n}^{*}\right) \Phi\left(z_{n}^{*}-t_{n}^{*}\right)-\left[\phi\left(z_{n}^{*}-t_{n}^{*}\right)+z_{n}^{*} \Phi\left(z_{n}^{*}-t_{n}^{*}\right)\right]\right] .
\end{aligned}
$$

\footnotetext{
${ }^{11}$ The date-0 participation constraint requiring the manager to achieve expected utility at least as great as $\bar{U}$ prior to exerting entrepreneurial effort is implied by the other constraints in equilibrium. Under the constraints (IC1), (IC2) and (IR), we show below that the manager's expected payoff from playing the direct revelation mechanism is the sum of $\bar{U}$ and her expected information rent which is always positive even when she chooses entrepreneurial effort $z=0$. In other words, the manager can get at least $\bar{U}$ by exerting zero entrepreneurial effort; therefore, with optimal entrepreneurial effort, the manager's expected net payoff must be greater than $\bar{U}$, and thus the date- 0 participation constraint is satisfied.
} 
Lemma 1. (i) Eqs. (1)-(3) have a unique solution $\left(\lambda_{n}^{*}, z_{n}^{*}, t_{n}^{*}\right)$; and $\lambda_{n}^{*}, z_{n}^{*}, t_{n}^{*}>0$.

(ii) $z_{n}^{*}$ and $\lambda_{n}^{*}$ increase in $\delta$ and $\theta$, and decrease in $\gamma$.

Proof: See the Appendix.

Clearly $\lambda_{n}^{*}, z_{n}^{*}$ and $t_{n}^{*}$ are all independent of $\sigma$ (the subscript $n$ stands for "normalization" by $\sigma)$. We now state our main result.

Proposition 2. The optimal mechanism can be implemented with a linear compensation contract, $w^{*}(t, V)=a^{*}(t)+b^{*}(t) V$, and the capital allocation, $k^{*}(t)$, given by:

(i) If $t<0, b^{*}(t)=k^{*}(t)=0$.

(ii) If $0 \leq t<t^{*}=\sigma t_{n}^{*}, b^{*}(t)=0$ and $k^{*}(t)=\delta t$.

(iii) If $t \geq t^{*}$, then

$$
\begin{aligned}
b^{*}(t) & =1+\left(\frac{\gamma}{\theta^{2}}-1\right) \frac{\lambda_{n}^{*}-\mu\left(t / \sigma-z_{n}^{*}\right)}{t / \sigma+\lambda_{n}^{*}-\mu\left(t / \sigma-z_{n}^{*}\right)} \\
k^{*}(t) & =\frac{\gamma \delta}{\gamma-\theta^{2}}\left[t+\sigma\left(\lambda_{n}^{*}-\mu\left(t / \sigma-z_{n}^{*}\right)\right)\right] .
\end{aligned}
$$

(iv) The fixed salary is given by

$$
a^{*}(t)=\bar{U}+\int_{-\infty}^{t} \delta b^{*}(s) k(s) d s-\delta b^{*}(t) k^{*}(t) t+0.5 b^{*}(t) k^{*}(t)^{2}\left[1-\theta^{2} b^{*}(t) / \gamma\right]
$$

(v) The managerial effort is $x^{*}(t)=\theta b^{*}(t) k^{*}(t) / \gamma$.

(vi) The entrepreneurial effort is $z^{*}=\sigma z_{n}^{*}$.

Proof: See the Appendix.

Our optimal mechanism has three regions. If the manager reports that the project is in the low-quality region $(t<0)$, the firm allocates no capital. If the manager reports that the project is in the intermediate-quality region $\left(0 \leq t<t^{*}\right)$, the firm funds the project but does not provide incentives for the manager to exert managerial effort. If the manager 
reports that the project is in the high-quality region $\left(t \geq t^{*}\right)$, the firm funds the project and also provides incentives for the manager to exert managerial effort to increase the project's expected cash flows. The most interesting aspect of the optimal mechanism is that the firm need not invest in all projects to motivate entrepreneurial effort; instead, it is optimal for the firm to fund only the best projects.

There are two keys to understanding the optimal mechanism. First, we show in the proof of Proposition 2 (in the Appendix) that the set of contracts that induce managerial truth-telling can be characterized by:

$$
U(t)=\bar{U}+\delta \int_{-\infty}^{t} b(s) k(s) d s
$$

The firm can motivate a manager of type $t$ to report truthfully by offering a contract that provides the manager a level of utility $U(t)$ where the term $\delta \int_{-\infty}^{t} b(s) k(s) d s$ is the type- $t$ manager's information rent. Many contracts induce truthtelling but some are better than others. For example, the contract $b(t)=0$ for all $t$ will motivate the manager to tell the truth but not to exert managerial effort (since she doesn't share in the future cash flows). Importantly, because of the truth-telling IC constraint (IC2), the cost of offering incentive pay and capital spills over into the information rents that must be paid to all managers with higher quality projects. Thus, the cost of incentive provision and capital for lowquality projects can be exceedingly high. Consequently, the firm only provides incentive pay and capital to the highest-quality projects.

Second, the equilibrium level of entrepreneurial effort is given by:

$$
z=\frac{\delta}{\gamma} \int_{-\infty}^{\infty} b(t) k(t) \frac{1}{\sigma} \phi\left(\frac{t-z}{\sigma}\right) d t .
$$

The firm can motivate entrepreneurial effort by increasing incentive pay, $b(t)$, and/or by increasing the capital allocation, $k(t)$. This is intuitive since the manager will not exert entrepreneurial effort if she doesn't believe the project will be funded appropriately or if she does not get to participate in its success. As we showed above, however, it is relatively inexpensive for the firm to offer extra incentive pay and capital for higher quality projects. 
This has important consequences for the firm's optimal compensation and investment policy as the following corollary demonstrates.

Corollary 1. (i) For sufficiently high project quality t, the firm provides excessive pay for performance, i.e., $b^{*}(t)>1$.

(ii) $b^{*}(t)$ is increasing (decreasing) for low (high) $t$ : there exists $t_{1}>t^{*}$ such that $\forall t \leq t_{1}$, $d b^{*}(t) / d t \geq 0 ;$ and $\forall t>t_{1}, d b^{*}(t) / d t<0$.

(iii) The capital allocation, $k^{*}(t)$, and managerial effort, $x^{*}(t)$, are both increasing in $t$;

(iv) The optimal managerial effort and capital allocation are lower than the first-best for low project qualities, and are higher than the first-best for high project qualities, i.e., there exists $\bar{t}>t^{*}$ such that $\forall t \leq \bar{t}, x^{*}(t) \leq x^{f b}(t)$ and $k^{*}(t) \leq k^{f b}(t)$; and $\forall t>\bar{t}$, $x^{*}(t)>x^{f b}(t)$ and $k^{*}(t)>k^{f b}(t)$.

Proof: See the Appendix.

The most interesting result is that for sufficiently high project qualities, the firm optimally overinvests (relative to first-best) and provides very high powered incentives $\left(b^{*}(t)>1\right)$ resulting in an oversupply of managerial effort (relative to first-best). To provide intuition, suppose $t \geq t^{*}$ so we can rewrite the second-best managerial effort and capital allocation as follows:

$$
\begin{aligned}
x^{*}(t) & =x^{f b}(t)+\frac{\gamma \delta}{\theta\left(\gamma-\theta^{2}\right)}\left[\sigma \lambda_{n}^{*}-\sigma \mu\left(t / \sigma-z_{n}^{*}\right)\right] \\
k^{*}(t) & =k^{f b}(t)+\frac{\gamma \delta}{\gamma-\theta^{2}}\left[\sigma \lambda_{n}^{*}-\sigma \mu\left(t / \sigma-z_{n}^{*}\right)\right] .
\end{aligned}
$$

The quantity $\sigma \lambda_{n}^{*}$ represents the shadow value of entrepreneurial effort and the optimal entrepreneurial effort is equal to $\sigma z_{n}^{*}$. First, consider the case in which entrepreneurial effort has no value $\left(\lambda_{n}^{*}=z_{n}^{*}=0\right) .{ }^{12}$ Since $\mu>0$, there is underinvestment in both managerial

\footnotetext{
${ }^{12}$ This case is studied in Bernardo, Cai, and Luo (2001).
} 
effort and capital. The reason is that the optimal mechanism must only strike a balance between providing incentives for managerial effort and encouraging truthful reporting. We showed earlier, however, that any commitment to increase the information rents for a given realization of project quality must also include a commitment to offer at least as much rents to the manager for all higher realizations of project quality otherwise she will not report truthfully. This makes the costs of providing incentive very high, especially for low-quality projects for which there are many projects of higher quality. This distortion is captured by the inverse hazard rate function, $\mu$, and it causes the firm to optimally provide too few incentives for managerial effort and allocate too little capital (since managerial effort and capital are complementary by assumption) relative to first-best. Moreover, the distortion from first-best is decreasing in the manager's type (since $\mu^{\prime}<0$ ) and vanishes for the highest type $(t \rightarrow \infty)$.

Now suppose the entrepreneneurial effort has value $\left(\lambda_{n}^{*}>0\right)$, i.e., the investment opportunity set is not fixed. The manager must decide how much entrepreneurial effort to exert at date 1 (prior to observing a specific $t$ ) so the firm can only motivate the manager to provide such effort by offering expected compensation (expectation over $t$ ) that increases in $z$. This can be achieved by increasing incentive pay and/or by increasing the capital allocation but, as we showed above, it is relatively inexpensive for the firm to do this for high-quality projects. Thus, the firm increases performance pay and capital only for the highest quality projects and, since in the absence of entrepreneurial effort incentive pay and capital approach the first-best as project quality approaches its upper limit, there exists a threshold quality level, $t^{*}$, beyond which the firm provides more capital and incentives than in the first-best.

As can be seen from Equation (4), performance pay and capital can be equally effective in motivating entrepreneurial effort, however, excessive capital causes less distortion than excessive performance pay for high quality projects because capital is more directly productive when project quality is higher (through the term $\delta t k$ ). Thus, the firm prefers overinvesting capital rather than providing excessive performance pay as the project qual- 
ity increases so that both capital and capital overinvestment is increasing in $t$. In contrast, performance pay decreases beyond a certain level of project quality and converges to the first best level of one as $t$ approaches its upper limit.

It is difficult to ascertain the effect of the investment and compensation policy on entrepreneurial effort. Although the firm aggressively funds projects and provides very powerful performance incentives for high quality projects, the manager chooses entrepreneurial effort prior to observing project quality. We can show that entrepreneneurial effort in the optimal mechanism is less than the first-best when $\delta$ is sufficiently small, i.e., the effect of the underprovision of capital and incentives for low-quality projects dominates the effect of the overprovision of capital and incentives for high-quality projects. While we believe that this result holds more generally we cannot prove it. ${ }^{13}$

\section{A. Uncertainty, incentives, and capital allocation}

The parameter $\sigma$ represents the dispersion of potential project qualities and is a measure of the uncertainty of the economic environment. The following corollary describes the monotonicity of the optimal mechanism in $\sigma$.

Corollary 2. (i) In the optimal mechanism, the sensitivity of pay to performance, $b^{*}(t)$, managerial effort, $x^{*}(t)$, and capital allocation, $k^{*}(t)$, decrease in $\sigma$ (uncertainty) for low project qualities, and increases in $\sigma$ for high project qualities, i.e., there exists $t_{1}>t^{*}$ such that $\forall t \leq t_{1}, \partial b^{*} / \partial \sigma, \partial x^{*} / \partial \sigma, \partial k^{*} / \partial \sigma \leq 0 ;$ and $\forall t>t_{1}, \partial b^{*} / \partial \sigma, \partial x^{*} / \partial \sigma, \partial k^{*} / \partial \sigma>$ 0.

(ii) The optimal entrepreneurial effort, $z^{*}$, increases in $\sigma$, i.e., $\partial z^{*} / \partial \sigma>0$.

Proof: See the Appendix.

\footnotetext{
${ }^{13}$ The main difficulty lies in the fact that both managerial effort and capital allocation can be greater than the first-best levels beyond the threshold project quality $t^{*}$. From Equation (4), it is not easy to show that the right-hand side is lower than the first-best solution.
} 
In the first-best solution, the optimal managerial effort and capital allocation are independent of $\sigma$ because both the firm and the manager are risk neutral and there are no information or incentive problems. In the second-best mechanism, higher $\sigma$ has two effects. First, higher $\sigma$ implies a higher shadow value of entrepreneurial effort $\left(\sigma \lambda_{n}^{*}\right)$ which makes it optimal for the firm to offer extra incentive pay and capital. Second, higher $\sigma$ exacerbates the already high cost of doing this for low $t$ because the expected cost of increasing information rents to all higher $t$ is increasing when there is more probability mass in the tails. Overall, when $\sigma$ increases, it is efficient to increase (decrease) incentive pay and capital for high (low) quality projects which, in turn, provides more (less) incentives for managerial effort.

Interestingly, there is a robust region in which incentive pay increases in uncertainty. This prediction is contrary to the standard principal-agent model. In the standard model, a risk-neutral firm must provide incentive pay to motivate a risk-averse manager to provide valuable but privately costly (managerial) effort and the only uncertainty is measurement error. The manager's effort is assumed to be additive and non-stochastic so that the marginal benefit of incentive pay is independent of uncertainty; however, the marginal cost of incentive pay is increasing in uncertainty because the manager is risk-averse. Thus, the standard model predicts that uncertainty and incentives are negatively related. Recent empirical evidence finds ambiguous results (Prendergast, 2002). In our model, both the benefits and costs of providing incentive pay depend on the uncertainty of the economic environment. In particular, when the underlying uncertainty of the business is high, motivating entrepreneurial activity by offering extra pay for performance (for upper range of project qualities) is more valuable; thus, we get a robust region in which uncertainty and the sensitivity of pay to performance are positively related. ${ }^{14}$

\footnotetext{
${ }^{14}$ The presence of entrepreneurial effort is critical for this result. If we assume entrepreneurial effort is not valuable so that $\lambda^{*}=z^{*}=0$ and follow the proof of Corollary 2, we can immediately show that the incentive pay, managerial effort, and capital allocation are all decreasing in $\sigma$ which is in sharp contrast to the case when entrepreneurial effort is important.
} 


\section{B. Entrepreneurial activity and the funding of internal ventures}

The following result shows when the manager engages in more or less entrepreneurial activity.

Corollary 3. (i) Entrepreneurial effort, $z^{*}$, increases in $\delta$ (the importance of project quality) and $\theta$ (the importance of managerial effort); and decreases in $\gamma$ (the cost of effort).

(ii) For sufficiently high project qualities, the overinvestment in capital, $k^{*}(t)-k^{f b}(t)$, and in managerial effort, $x^{*}(t)-x^{f b}(t)$, increases in $\delta$ and $\theta$; and decreases in $\gamma$.

Proof: See the Appendix.

The comparative statics for the entrepreneurial effort $z^{*}$ in the optimal mechanism are identical to the first-best, i.e., the shadow value of entrepreneurial effort $\left(\sigma \lambda_{n}^{*}\right)$ is increasing in $\delta$ and $\theta$ while the cost of entrepreneurial effort increases in $\gamma$. The firm can motivate entrepreneurial effort by increasing its capital expenditures and thus, for the highest quality projects, the overinvestment in capital (relative to first-best) also increases in $\delta$ and $\theta$ and decreases in $\gamma$.

For what follows, it will be useful to interpret our key parameters. The parameter $\delta$ represents the relevance of the manager's private information for the project cash flows, thus we expect $\delta$ to be greater, for example, when the firm is early in its lifecycle or in a high-growth industry. The parameter $\theta$ represents the importance of unverifiable managerial effort, thus we expect $\theta$ to be greater, for example, when the manager's job tasks require more firm-specific human capital. Finally, the parameter $\gamma$ represents effort cost; however, an alternative and more empirically useful interpretation of $1 / \gamma$ (more generally, the inverse of the second derivative of the cost function $\left.1 / g^{\prime \prime}(x)\right)$ is the responsiveness of unverifiable actions to an increase in incentives (Milgrom and Roberts, 1992). In this interpretation, $\gamma$ is lower when the manager has more discretion which is more likely true 
if, for example, the firm's board of directors is ineffective or the firm is diversified so the board of directors lacks the expertise to monitor the management.

Thus, we predict there will be more entrepreneurial activity when (i) the firm is early in its lifecycle or in a high-growth industry; (ii) the division managers require more firmspecific human capital; (iii) the board is less effective at monitoring managers; or (iv) the firm is diversified. The firm is also more likely to aggressively fund high-quality projects in such cases thus predictions (i) and (iv) are consistent with the empirical evidence that young, high-growth firms and diversified firms are less likely to "spawn" new venture capital backed startups (Gompers, Lerner and Scharfstein, 2005). Our model shows that these types of firms are more likely to motivate entrepreneurial activity by heavily funding internal ventures and thus workers choose to stay at their firms because they perceive the rents from doing so are high.

\section{Robustness: Distribution of project quality}

Although we assume that the project quality $t$ is normally distributed in our model, the existence of an overinvestment region holds for more general distributions. For example, suppose that conditional on the entrepreneurial effort $z, t$ has a distribution function of $F(t \mid z)$ and density function $f(t \mid z)>0$ with a decreasing inverse hazard rate $\mu(t \mid z)=[1-F(t \mid z)] / f(t \mid z)$. Also, suppose that $z$ shifts the distribution function $F(t \mid z)$ in the sense of first-order stochastic dominance, i.e., $F_{z}(t \mid z) \leq 0, \forall t$; in particular, $\lim _{t \rightarrow \infty}\left[F_{z}(t \mid z) / f(t \mid z)\right]<0$.

By following the derivation in the proof of Proposition 2, we can immediately show that the optimal level of managerial effort and capital allocation become

$$
\begin{aligned}
& x^{*}(t)=x^{f b}(t)+\frac{\delta \gamma}{\theta\left(\gamma-\theta^{2}\right)}\left[\lambda^{*}\left(-\frac{F_{z}(t \mid z)}{f(t \mid z)}\right)-\mu(t \mid z)\right], \\
& k^{*}(t)=k^{f b}(t)+\frac{\delta \gamma}{\gamma-\theta^{2}}\left[\lambda^{*}\left(-\frac{F_{z}(t \mid z)}{f(t \mid z)}\right)-\mu(t \mid z)\right],
\end{aligned}
$$

where $\lambda^{*}>0$ is the shadow value of entrepreneurial effort. A sufficient condition for the 
results in Corollary 1 to hold is that as $t \rightarrow \infty, \mu(t \mid z) \rightarrow 0$. Thus, in this more general case, the firm provides extra incentive and allocates too much capital (relative to first-best) for high-quality projects.

\section{Conclusions}

There is a considerable literature studying venture capital financing of start-up companies but relatively little work on how established firms develop and fund internal ventures. In this paper, we argue that established firms have an incentive to commit to ex post inefficient investment policies to effectively screen information from better-informed managers and to motivate managers to engage in entrepreneurial activity. We show that rather than funding all internal ventures the firm optimally overinvests, relative to first-best, in high-quality ventures and underinvests, relative to first-best, in low-quality ventures. We also show that young, high-growth and/or diversified firms are more likely to follow these practices; thus workers in these firms can receive high rents if they choose to stay. Consistent with this prediction, Gompers, Lerner, and Scharfstein (2005) present empirical evidence that these firms "spawn" less, i.e., workers in these types of firms are less likely to leave their firms to start their own ventures. Finally, unlike the standard principal-agent model but consistent with recent empirical findings (see, e.g., Prendergast, 2002), we predict that incentives can be positively related to the uncertainty in the economic environment. 


\section{Appendix}

Proof of Proposition 1. The f.o.c.s for the first-best (interior) solutions are

$$
\begin{aligned}
0 & =\delta t+\theta x-k \\
0 & =\theta k-\gamma x \\
0 & =-\frac{1}{\sigma} \int_{-\infty}^{\infty}\left[(\delta t+\theta x) k-0.5 k^{2}-0.5 \gamma x^{2}\right] d \phi\left(\frac{t-z}{\sigma}\right)-\gamma z
\end{aligned}
$$

The first two f.o.c.s (for $k$ and $x$ ) imply

$$
\begin{aligned}
k^{f b}(t) & =\frac{\gamma \delta}{\gamma-\theta^{2}} \max (0, t), \\
x^{f b}(t) & =\frac{\theta \delta}{\gamma-\theta^{2}} \max (0, t) .
\end{aligned}
$$

Substituting the optimal $x^{f b}(t)$ and $k^{f b}(t)$ into the third f.o.c. (for $z$ ) yields

$$
0=-0.5 \frac{1}{\sigma} \frac{\gamma \delta^{2}}{\gamma-\theta^{2}} \int_{0}^{\infty} t^{2} d \phi\left(\frac{t-z}{\sigma}\right)-\gamma z=\frac{\gamma \delta^{2}}{\gamma-\theta^{2}}\left[z \Phi\left(\frac{z}{\sigma}\right)+\sigma \phi\left(\frac{z}{\sigma}\right)\right]-\gamma z
$$

Therefore, it can be expressed $z^{f b}=\sigma z_{n}^{f b}$ where $z_{n}^{f b}$ is determined by

$$
0=\frac{\delta^{2}}{\gamma}\left[\phi\left(z_{n}^{f b}\right)+z_{n}^{f b} \Phi\left(z_{n}^{f b}\right)\right]-\left(1-\frac{\theta^{2}}{\gamma}\right) z_{n}^{f b} .
$$

The s.o.c.s hold under Assumption (A1).

To show that this equation has a unique and positive solution, define a function

$$
G(y) \equiv \frac{\delta^{2}}{\gamma}[\phi(y)+y \Phi(y)]-\left(1-\frac{\theta^{2}}{\gamma}\right) y
$$

It suffices to show $G(y)=0$ has a unique and positive solution. Note that

$$
\begin{aligned}
\frac{d G}{d y} & =\frac{\delta^{2}}{\gamma} \Phi(y)-\left(1-\frac{\theta^{2}}{\gamma}\right)<\frac{\delta^{2}+\theta^{2}-\gamma}{\gamma}<0, \\
G(0) & >0, \\
G(\infty) & =\frac{\delta^{2}}{\gamma} \lim _{y \rightarrow \infty} \phi(y)-\left(1-\frac{\theta^{2}}{\gamma}\right) \lim _{y \rightarrow \infty} y\left[1-\frac{\delta^{2}}{\gamma-\theta^{2}} \Phi(y)\right] \rightarrow-\infty,
\end{aligned}
$$

where the inequalities follow from Assumption (A1). Therefore, there is a unique and positive solution to $G(y)=0$.

The properties of $k^{f b}(t)$ and $x^{f b}(t)$ are obvious. Since $z_{n}^{f b}$ does not depend on $\sigma, z^{f b}=\sigma z_{n}^{f b}$ increases in $\sigma$. Under Assumption (A1),

$$
\frac{\partial z_{n}^{f b}}{\partial\left(\delta^{2}\right)}=-\frac{\phi\left(z_{n}^{f b}\right)+z_{n}^{f b} \Phi\left(z_{n}^{f b}\right)}{\delta^{2} \Phi\left(z_{n}^{f b}\right)+\theta^{2}-\gamma}>0 .
$$


Therefore, $z^{f b}$ increases in $\delta$. Similarly, $z^{f b}$ increases in $\theta$, and decreases in $\gamma$.

Q.E.D.

Proof of Lemma 1. There are four steps in what follows. In step 1, we show that $\lambda_{n}^{*}$ can be viewed as a function of $z_{n}^{*}$; and given $z_{n}^{*}>0$, it must be $\lambda_{n}^{*}>0$. In step 2, we show that $t_{n}^{*}$ can be viewed as a function of $z_{n}^{*}$; and given $z_{n}^{*}>0$, it must be $t_{n}^{*}>0$. In step 3 , we treat $\lambda_{n}^{*}$ and $t_{n}^{*}$ as functions of $z_{n}^{*}$, and show that a positive $z_{n}^{*}$ is uniquely determined. In step 4 , we prove the monotonicities of $z_{n}^{*}$ and $\lambda_{n}^{*}$.

Step 1: According to Eq. (1), $\lambda_{n}^{*}$ can be viewed as a function of $z_{n}^{*}$. In particular, if $z_{n}^{*}>0, \lambda_{n}^{*}>0$.

Step 2: Substituting Eq. (1) into Eq. (2) yields

$$
0=t_{n}^{*}+\frac{\gamma}{\theta^{2}}\left[\frac{\delta^{2}}{\gamma}\left[\phi\left(z_{n}^{*}\right)+z_{n}^{*} \Phi\left(z_{n}^{*}\right)\right]+\frac{\theta^{2}}{\gamma} z_{n}^{*}-\mu\left(t_{n}^{*}-z_{n}^{*}\right)\right] .
$$

Define the right hand side of the equation as function $I\left(t_{n}^{*}, z_{n}^{*}\right)$. Note

$$
\begin{aligned}
\frac{\partial I}{\partial t_{n}^{*}} & =1-\frac{\gamma}{\theta^{2}} \mu^{\prime}\left(t_{n}^{*}-z_{n}^{*}\right)>0 \\
I\left(-\infty, z_{n}^{*}\right) & <\lim _{t_{n}^{*} \rightarrow-\infty} t_{n}^{*}+\frac{\gamma}{\theta^{2}}\left[\frac{\delta^{2}}{\gamma}\left[\phi\left(z_{n}^{*}\right)+z_{n}^{*} \Phi\left(z_{n}^{*}\right)\right]+\frac{\theta^{2}}{\gamma} z_{n}^{*}\right]<0, \\
I\left(\infty, z_{n}^{*}\right) & >\lim _{t_{n}^{*} \rightarrow \infty}\left[t_{n}^{*}-\frac{\gamma}{\theta^{2}} \mu\left(t_{n}^{*}-z_{n} *\right)\right]+\frac{\gamma}{\theta^{2}}\left[\frac{\delta^{2}}{\gamma}\left[\phi\left(z_{n}^{*}\right)+z_{n}^{*} \Phi\left(z_{n}^{*}\right)\right]+\frac{\theta^{2}}{\gamma} z_{n}^{*}\right]>0,
\end{aligned}
$$

from the facts $\mu^{\prime}<0$ and $\lim _{y \rightarrow \infty} \mu(y)=0$. Thus for given $z_{n}^{*}, t_{n}^{*}$ is uniquely determined by $I\left(t_{n}^{*}, z_{n}^{*}\right)=0$, and can be viewed as a function of $z_{n}^{*}$.

Also note, if $z_{n}^{*}>0$, then

$$
\begin{aligned}
I(0,0) & =\frac{\gamma}{\theta^{2}}\left[\frac{\delta^{2}}{\gamma} \phi(0)-\mu(0)\right]<\frac{\gamma}{\theta^{2}}[\phi(0)-\mu(0)] \approx 0.4-0.5 / 0.4<0, \\
\frac{\partial I\left(0, z_{n}^{*}\right)}{\partial z_{n}^{*}} & =\frac{\gamma}{\theta^{2}}\left[\frac{\delta^{2}}{\gamma} \Phi\left(z_{n}^{*}\right)+\frac{\theta^{2}}{\gamma}-1-z_{n}^{*} \mu\left(-z_{n}^{*}\right)\right]<\frac{\gamma}{\theta^{2}}\left[\frac{\delta^{2}+\theta^{2}}{\gamma}-1\right]<0,
\end{aligned}
$$

where the second equality follows from $\mu^{\prime}(y)=-1+y \mu(y)$; thus, $I\left(0, z_{n}^{*}\right)<0$. Combined with the facts $\partial I / \partial t_{n}^{*}>0$ and $I\left(\infty, z_{n}^{*}\right)>0, t_{n}^{*}$ that is uniquely determined by $I\left(t_{n}^{*}, z_{n}^{*}\right)=0$ must be positive for given $z_{n}^{*}>0$.

Step 3: So far we have shown that $\lambda_{n}^{*}$ and $t_{n}^{*}$ can be viewed as functions of $z_{n}^{*}$ according to Eqs. (1)-(2); if $z_{n}^{*}>0, \lambda_{n}^{*}$ and $t_{n}^{*}$ are positive. To prove Lemma 1 , it suffices to show that $z_{n}^{*}$ is uniquely determined and is positive.

According to Eq. (3), define a function of $z_{n}^{*}$

$$
H\left(z_{n}^{*}\right)=\frac{\delta^{2}}{\theta^{2}}\left[\frac{\gamma}{\gamma-\theta^{2}}\left(t_{n}^{*}+\lambda_{n}^{*}\right) \Phi\left(z_{n}^{*}-t_{n}^{*}\right)-\left[\phi\left(z_{n}^{*}-t_{n}^{*}\right)+z_{n}^{*} \Phi\left(z_{n}^{*}-t_{n}^{*}\right)\right]\right]-z_{n}^{*} .
$$

For $z_{n}^{*}$ to be uniquely determined and to be positive, we just need to show $d H / d z_{n}^{*}<0, H(0)>0$ and $H(\infty)<0$. 
It can be verified that

$$
\begin{aligned}
\frac{\partial H}{\partial t_{n}^{*}} & =0 \\
\frac{\partial H}{\partial z_{n}^{*}} & =\frac{\delta^{2}}{\gamma-\theta^{2}} \Phi\left(z_{n}^{*}-t_{n}^{*}\right)-1 \\
\frac{\partial H}{\partial \lambda_{n}^{*}} & =\frac{\delta^{2}}{\theta^{2}} \frac{\gamma}{\gamma-\theta^{2}} \Phi\left(z_{n}^{*}-t_{n}^{*}\right) .
\end{aligned}
$$

Therefore,

$$
\begin{aligned}
\frac{d H}{d z_{n}^{*}} & =\frac{\partial H}{\partial z_{n}^{*}}+\frac{\partial H}{\partial \lambda_{n}^{*}} \frac{d \lambda_{n}^{*}}{d z_{n}^{*}}+\frac{\partial H}{\partial t_{n}^{*}} \frac{d t_{n}^{*}}{d z_{n}^{*}} \\
& =\frac{\delta^{2}}{\theta^{2}}\left[\frac{2 \theta^{2}}{\gamma-\theta^{2}} \Phi\left(z_{n}^{*}-t_{n}^{*}\right)+\frac{\delta^{2}}{\gamma-\theta^{2}} \Phi\left(z_{n}^{*}-t_{n}^{*}\right) \Phi\left(z_{n}^{*}\right)\right]-1 \\
& <\frac{\delta^{2}}{\theta^{2}} \frac{2 \theta^{2}+\delta^{2}}{\gamma-\theta^{2}}-1 \\
& <0
\end{aligned}
$$

where the last inequality follows from Assumption (A1).

Suppose $z_{n}^{*}=0$. Then $\lambda_{n}^{*}=\frac{\delta^{2}}{\gamma} \phi(0) ;$ and $t_{n}^{*}$ is determined by $t_{n}^{*}=\frac{\gamma}{\theta^{2}}\left(\mu\left(t_{n}^{*}\right)-\lambda_{n}^{*}\right)=\frac{\gamma}{\theta^{2}}\left(\mu\left(t_{n}^{*}\right)-\right.$ $\left.\frac{\delta^{2}}{\gamma} \phi(0)\right)$. Define a function

$$
J\left(t_{n}^{*}\right)=t_{n}^{*}-\frac{\gamma}{\theta^{2}}\left(\mu\left(t_{n}^{*}\right)-\frac{\delta^{2}}{\gamma} \phi(0)\right)
$$

then

$$
\begin{aligned}
J(0.75) & =0.75-\frac{\gamma}{\theta^{2}}\left(\mu(0.75)-\frac{\delta^{2}}{\gamma} \phi(0)\right)=\frac{1}{\theta^{2}}\left[0.75 \theta^{2}+\delta^{2} \phi(0)-\gamma \mu(0.75)\right] \\
& \approx \frac{1}{\theta^{2}}\left[0.75 \theta^{2}+0.4 \delta^{2}-0.752 \gamma\right]<\frac{0.75}{\theta^{2}}\left[\theta^{2}+\delta^{2}-\gamma\right]<0,
\end{aligned}
$$

where the last inequality follows from Assumption (A1). Since $d J / d t_{n}^{*}>0$, the $t_{n}^{*}$ determined by $J\left(t_{n}^{*}\right)=0$ must be greater than 0.75 . Therefore, at $z_{n}^{*}=0, t_{n}^{*}>0.75$. We then have

$$
\begin{aligned}
H(0) & =\frac{\delta^{2}}{\theta^{2}}\left[\frac{\gamma}{\gamma-\theta^{2}}\left(t_{n}^{*}+\lambda_{n}^{*}\right) \Phi\left(-t_{n}^{*}\right)-\phi\left(t_{n}^{*}\right)\right] \\
& =\frac{\delta^{2}}{\theta^{2}} \phi\left(t_{n}^{*}\right)\left[\frac{\gamma}{\gamma-\theta^{2}}\left(t_{n}^{*}+\lambda_{n}^{*}\right)\left(\frac{\theta^{2}}{\gamma} t_{n}^{*}+\lambda_{n}^{*}\right)-1\right] \\
& >\frac{\delta^{2} \phi\left(t_{n}^{*}\right)}{\theta^{2}\left(\gamma-\theta^{2}\right)}\left[\theta^{2} t_{n}^{* 2}-\left(\gamma-\theta^{2}\right)\right] \\
& >\frac{\delta^{2} \phi\left(t_{n}^{*}\right)}{\theta^{2}\left(\gamma-\theta^{2}\right)}\left(\theta^{2} \frac{25}{16}-\gamma\right) \\
& >0
\end{aligned}
$$


where the last inequality follows from Assumption (A2). Therefore, $H(0)>0$.

As $z_{n}^{*} \rightarrow \infty$, clearly $\lambda_{n}^{*} \rightarrow \infty$. From Eq. (2), it must be that $t_{n}^{*} \rightarrow \infty$. Otherwise, the left hand side of Eq. (2) is a finite $t_{n}^{*}$; however, since

$$
\begin{aligned}
\lim _{z_{n}^{*} \rightarrow \infty} \frac{\mu\left(t_{n}^{*}-z_{n}^{*}\right)}{z_{n}^{*}} & =\lim _{z_{n}^{*} \rightarrow \infty}\left[1+\mu\left(t_{n}^{*}-z_{n}^{*}\right)\left(z_{n}^{*}-t_{n}^{*}\right)\right]=\infty, \\
\lim _{z_{n}^{*} \rightarrow \infty} \frac{\lambda_{n}^{*}}{z_{n}^{*}} & =\frac{\theta^{2}+\delta^{2}}{\gamma}
\end{aligned}
$$

where the first equation uses the fact $\mu^{\prime}(y)=-1+y \mu(y)$, the RHS of Eq. (2) is

$$
\frac{\gamma}{\theta^{2}} \lim _{z_{n}^{*} \rightarrow \infty}\left[\mu\left(t_{n}^{*}-z_{n}^{*}\right)-\lambda_{n}^{*}\right]=\frac{\gamma}{\theta^{2}} \lim _{z_{n}^{*} \rightarrow \infty} z_{n}^{*}\left[\frac{\mu\left(t_{n}^{*}-z_{n}^{*}\right)}{z_{n}^{*}}-\frac{\lambda_{n}^{*}}{z_{n}^{*}}\right] \rightarrow \infty .
$$

This constitutes a contradiction. Therefore it must be that $t_{n}^{*} \rightarrow \infty$. It follows from Eq. (2) that $\mu\left(t_{n}^{*}-z_{n}^{*}\right) \rightarrow \infty$, hence $z_{n}^{*}-t_{n}^{*} \rightarrow \infty$. We then have

$$
\begin{aligned}
\frac{\theta^{2}}{\delta^{2}} \lim _{z_{n}^{*} \rightarrow \infty} \frac{H\left(z_{n}^{*}\right)}{z_{n}^{*}} & =\lim _{z_{n}^{*} \rightarrow \infty}\left[\frac{\gamma}{\gamma-\theta^{2}} \frac{t_{n}^{*}+\lambda_{n}^{*}}{z_{n}^{*}} \Phi\left(z_{n}^{*}-t_{n}^{*}\right)-\frac{\phi\left(z_{n}^{*}-t_{n}^{*}\right)+z_{n}^{*} \Phi\left(z_{n}^{*}-t_{n}^{*}\right)}{z_{n}^{*}}\right]-\frac{\theta^{2}}{\delta^{2}} \\
& =\frac{\gamma}{\gamma-\theta^{2}} \lim _{z_{n}^{*} \rightarrow \infty} \frac{t_{n}^{*}+\lambda_{n}^{*}}{z_{n}^{*}}-1-\frac{\theta^{2}}{\delta^{2}} \\
& \leq \frac{\gamma}{\gamma-\theta^{2}} \lim _{z_{n}^{*} \rightarrow \infty} \frac{z_{n}^{*}+\frac{\delta^{2}}{\gamma}\left[\phi\left(z_{n}^{*}\right)+z_{n}^{*} \Phi\left(z_{n}^{*}\right)\right]+\frac{\theta^{2}}{\gamma} z_{n}^{*}}{z_{n}^{*}}-1-\frac{\theta^{2}}{\delta^{2}} \\
& =\frac{\gamma}{\gamma-\theta^{2}} \frac{\gamma+\theta^{2}+\delta^{2}}{\gamma}-1-\frac{\theta^{2}}{\delta^{2}} \\
& <0,
\end{aligned}
$$

where the first inequality follows from $t_{n}^{*}<z_{n}^{*}$ in the limit since $z_{n}^{*}-t_{n}^{*} \rightarrow \infty$, and the last inequality holds under Assumption (A1). Therefore, $H(\infty)<0$.

To summarize, $d H / d z_{n}^{*}<0, H(0)>0, H(\infty)<0$. Therefore, $z_{n}^{*}$ is uniquely determined and is positive.

Step 4: Similar to the derivation of $d H / d z_{n}^{*}<0$, we have

$$
\begin{aligned}
\frac{d H}{d\left(\delta^{2}\right)}= & \frac{\partial H}{\partial\left(\delta^{2}\right)}+\frac{\partial H}{\partial \lambda_{n}^{*}} \frac{d \lambda_{n}^{*}}{d\left(\delta^{2}\right)}+\frac{\partial H}{\partial t_{n}^{*}} \frac{d t_{n}^{*}}{d\left(\delta^{2}\right)} \\
= & \frac{1}{\theta^{2}}\left[\frac{\gamma}{\gamma-\theta^{2}}\left(t_{n}^{*}+\lambda_{n}^{*}\right) \Phi\left(z_{n}^{*}-t_{n}^{*}\right)-\left[\phi\left(z_{n}^{*}-t_{n}^{*}\right)+z_{n}^{*} \Phi\left(z_{n}^{*}-t_{n}^{*}\right)\right]\right] \\
& +\frac{\delta^{2}}{\theta^{2}} \frac{\gamma}{\gamma-\theta^{2}} \Phi\left(z_{n}^{*}-t_{n}^{*}\right) \frac{1}{\gamma}\left[\phi\left(z_{n}^{*}\right)+z_{n}^{*} \Phi\left(z_{n}^{*}\right)\right] \\
= & \frac{z_{n}^{*}}{\delta^{2}}+\frac{\delta^{2}}{\theta^{2}} \frac{\gamma}{\gamma-\theta^{2}} \Phi\left(z_{n}^{*}-t_{n}^{*}\right) \frac{1}{\gamma}\left[\phi\left(z_{n}^{*}\right)+z_{n}^{*} \Phi\left(z_{n}^{*}\right)\right] \\
> & 0,
\end{aligned}
$$


where the third equality follows from the expression for $z_{n}^{*}$ in Eq. (3). Therefore, $d z_{n}^{*} / d\left(\delta^{2}\right)=-\left(d H / d\left(\delta^{2}\right)\right) /\left(d H / d z_{n}^{*}\right)>$ 0.

Still treat $\lambda_{n}^{*}$ as a function of $z_{n}^{*}$ specified in Eq. (1). Then

$$
\begin{aligned}
\frac{d \lambda_{n}^{*}}{d\left(\delta^{2}\right)} & =\frac{\partial \lambda_{n}^{*}}{\partial\left(\delta^{2}\right)}+\frac{\partial \lambda_{n}^{*}}{\partial z_{n}^{*}} \frac{d z_{n}^{*}}{d\left(\delta^{2}\right)} \\
& =\frac{1}{\gamma}\left[\phi\left(z_{n}^{*}\right)+z_{n}^{*} \Phi\left(z_{n}^{*}\right)\right]+\left[\frac{\delta^{2}}{\gamma} \Phi\left(z_{n}^{*}\right)+\frac{\theta^{2}}{\gamma}\right] \frac{d z_{n}^{*}}{d\left(\delta^{2}\right)} \\
& >0,
\end{aligned}
$$

from $d z_{n}^{*} / d\left(\delta^{2}\right)>0$. Therefore, $z_{n}^{*}$ and $\lambda_{n}^{*}$ increases in $\delta$.

Similarly we can show that $z_{n}^{*}$ and $\lambda_{n}^{*}$ increases (decreases) in $\theta(\gamma)$.

Q.E.D.

Proof of Proposition 2. Our proof follows the two-step approach of Laffont and Tirole (1986). In step 1, we consider a program (denoted $\mathrm{R}$ ) that relaxes some constraints in original optimization program (denoted P). With less stringent constraints, the firm should get at least the same expected payoff in Program R as in Program P. In step 2, we consider a program (denoted L) that uses compensation contracts linear in returns. Since Program L restricts to a narrower class of mechanisms, the firm can get at most the same expected payoff in Program L as in Program P. Finally, we demonstrate that the firm's expected payoffs from Programs R and L are the same. Consequently, the optimal solutions for all three Programs L, R and P must be the same.

Step 1: Consider a relaxed program, denoted $\mathrm{R}$, in which the firm can verify $\delta t+\theta \hat{x}$. In this hypothetical case, having reported $\hat{t}$, the manager must choose $\hat{x}$ so that $\delta t+\theta \hat{x}=\delta \hat{t}+\theta x(\hat{t})$. Otherwise, the firm would be sure that the manager had either lied about her true type or didn't exert the required managerial effort, and could punish her (arbitrarily) severely. Consequently, if the manager of a true type $t$ reports $\hat{t}$, she must choose $\hat{x}=x(\hat{t})+\delta(\hat{t}-t) / \theta$, resulting in the return of $V(\hat{t}, \epsilon)=(\delta \hat{t}+\theta x(\hat{t})) k(\hat{t})-0.5 k(\hat{t})^{2}+\epsilon$. Compared with Program P, the (IC1) constraint is completely relaxed in Program R.

In Program $\mathrm{R}$, if the manager of a true type $t$ reports $\hat{t}$, her expected payoff is

$$
U(t, \hat{t})=E_{\epsilon} w(\hat{t}, V(\hat{t}, \epsilon))-0.5 \gamma\left(x(\hat{t})+\frac{\delta(\hat{t}-t)}{\theta}\right)^{2} .
$$

By the Envelope Theorem,

$$
\frac{d U(t, t)}{d t}=\left.\frac{\partial U(t, \hat{t})}{\partial t}\right|_{\hat{t}=t}+\left.\frac{\partial U(t, \hat{t})}{\partial \hat{t}}\right|_{\hat{t}=t}=\left.\frac{\partial U(t, \hat{t})}{\partial t}\right|_{\hat{t}=t}=\frac{\delta \gamma x(t)}{\theta} .
$$

Integrating yields

$$
U(t)=U(-\infty)+\int_{-\infty}^{t} \frac{\delta \gamma x(s)}{\theta} d s
$$


This is the manager's expected payoff after she has expanded entrepreneurial effort $z$ and has observed the realization of project quality $t$ at date 1 ; the effort cost of $0.5 \gamma z^{2}$ is sunk. Imposing $U(-\infty)=\bar{U}$ from the (IR) constraint, and taking expectation yields

$$
\begin{aligned}
E U & =\bar{U}+\int_{-\infty}^{\infty} \int_{-\infty}^{t} \frac{\delta \gamma x(s)}{\theta} d s d \Phi\left(\frac{t-\hat{z}}{\sigma}\right) \\
& =\bar{U}+\int_{-\infty}^{\infty} \frac{\delta \gamma x(t)}{\theta}\left(1-\Phi\left(\frac{t-\hat{z}}{\sigma}\right)\right) d t
\end{aligned}
$$

The (IC3) constraint requires

$$
z \in \arg \max _{\hat{z}} \bar{U}+\int_{-\infty}^{\infty} \frac{\delta \gamma x(t)}{\theta}\left(1-\Phi\left(\frac{t-\hat{z}}{\sigma}\right)\right) d t-0.5 \gamma \hat{z}^{2}
$$

The f.o.c. for $z$ is

$$
\int_{-\infty}^{\infty} \frac{\delta \gamma x(t)}{\theta} \frac{1}{\sigma} \phi\left(\frac{t-z}{\sigma}\right) d t-\gamma z=0
$$

The s.o.c. will be verified after we have obtained the optimal mechanism.

Substituting the expression for wage, $E w=E U+0.5 \gamma E\left(x^{2}\right)$, into the firm' expected payoff yields

$$
\begin{aligned}
E \Pi & =\int_{-\infty}^{\infty}\left(E_{\epsilon} V-0.5 \gamma x^{2}-U\right) d \Phi\left(\frac{t-z}{\sigma}\right) \\
& =\int_{-\infty}^{\infty}\left[\left(\delta t k+\theta x k-0.5 k^{2}-0.5 \gamma x^{2}\right) \frac{1}{\sigma} \phi\left(\frac{t-z}{\sigma}\right)-\frac{\delta \gamma x}{\theta}\left(1-\Phi\left(\frac{t-z}{\sigma}\right)\right)\right] d t-\bar{U} .
\end{aligned}
$$

Denote $\lambda$ the Lagrangian multiplier for the IC constraint for $z$ (Eq. 9). The firm' maximum expected payoff can be expressed as:

$$
\begin{aligned}
E \Pi^{R}=\max _{k(t), x(t), z \geq 0, \lambda} & \int_{-\infty}^{\infty}\left[\left(\delta t k+\theta x k-0.5 k^{2}-0.5 \gamma x^{2}\right) \frac{1}{\sigma} \phi\left(\frac{t-z}{\sigma}\right)-\frac{\delta \gamma x}{\theta}\left(1-\Phi\left(\frac{t-z}{\sigma}\right)\right)\right] d t \\
& -\lambda\left(\gamma z-\int_{-\infty}^{\infty} \frac{\delta \gamma x}{\theta} \frac{1}{\sigma} \phi\left(\frac{t-z}{\sigma}\right) d t\right)-\bar{U} .
\end{aligned}
$$

Since Program R provides more flexibility to the firm to discipline the manager, it should yield the firm at least the same expected payoff as Program $\mathrm{P}$ does, i.e., $E \Pi^{R} \geq E \Pi^{P}$.

Step 2: Consider a program, denoted L, in which the firm is constrained to use compensation contracts linear in cash flows: $w(\hat{t}, V)=a(\hat{t})+b(\hat{t}) V$. Under this contract, the manager of type $t$ can get the following expected payoff from announcing $\hat{t}$ and choosing managerial effort $\hat{x}$ :

$$
U(t, \hat{t}, \hat{x})=a(\hat{t})+b(\hat{t})\left[(\delta t+\theta \hat{x}) k(\hat{t})-0.5 k(\hat{t})^{2}\right]-0.5 \gamma \hat{x}^{2}
$$

The f.o.c. for $\hat{x}$ is $\hat{x}=\theta b(\hat{t}) k(\hat{t}) / \gamma$. The s.o.c. holds obviously. 
Note the $\hat{x}$ depends only on $\hat{t}$. By the Envelope Theorem,

$$
\frac{d U(t, t)}{d t}=\left.\frac{\partial U(t, \hat{t})}{\partial t}\right|_{\hat{t}=t}+\left.\frac{\partial U(t, \hat{t})}{\partial \hat{t}}\right|_{\hat{t}=t}=\left.\frac{\partial U(t, \hat{t})}{\partial t}\right|_{\hat{t}=t}=\delta b(t) k(t) ;
$$

thus

$$
U(t)=U(-\infty)+\int_{-\infty}^{t} \delta b(s) k(s) d s .
$$

Imposing $U(-\infty)=\bar{U}$ and taking expectation yields

$$
\begin{aligned}
E U & =\bar{U}+\int_{-\infty}^{\infty} \int_{-\infty}^{t} \delta b(s) k(s) d s d \Phi\left(\frac{t-\hat{z}}{\sigma}\right) \\
& =\bar{U}+\int_{-\infty}^{\infty} \delta b(t) k(t)\left(1-\Phi\left(\frac{t-\hat{z}}{\sigma}\right)\right) d t .
\end{aligned}
$$

The (IC3) constraint requires

$$
z \in \arg \max _{\hat{z}} \bar{U}+\int_{-\infty}^{\infty} \delta b(t) k(t)\left(1-\Phi\left(\frac{t-\hat{z}}{\sigma}\right)\right) d t-0.5 \gamma \hat{z}^{2} .
$$

The f.o.c. for $z$ is

$$
\begin{aligned}
\int_{-\infty}^{\infty} \delta b(t) k(t) \frac{1}{\sigma} \phi\left(\frac{t-z}{\sigma}\right) d t-\gamma z & =0 \\
\int_{-\infty}^{\infty} \frac{\delta \gamma x(t)}{\theta} \frac{1}{\sigma} \phi\left(\frac{t-z}{\sigma}\right) d t-\gamma z & =0
\end{aligned}
$$

where the second equality obtains by substituting the expression for $x(t)$. The s.o.c. is easily satisfied as long as $x(t)$ is integrable, which is the case in the optimal mechanism. ${ }^{15}$

Substituting the expression for wages, $E w=E U+0.5 \gamma E\left(x^{2}\right)$, into the firm' expected payoff yields

$$
\begin{aligned}
E \Pi & =\int_{-\infty}^{\infty}\left(V-0.5 \gamma x^{2}-U\right) d \Phi\left(\frac{t-z}{\sigma}\right) \\
& =\int_{-\infty}^{\infty}\left[\left(\delta t k+\theta x k-0.5 k^{2}-0.5 \gamma x^{2}\right) \frac{1}{\sigma} \phi\left(\frac{t-z}{\sigma}\right)-\frac{\delta \gamma x}{\theta}\left(1-\Phi\left(\frac{t-z}{\sigma}\right)\right)\right] d t-\bar{U} .
\end{aligned}
$$

Denote $\lambda$ as the Lagrangian multiplier for the IC constraint for $z$ (Eq. 12). The firm's mechanism design problem can be expressed as:

$$
\begin{aligned}
E \Pi^{L}=\max _{k(t), x(t), z \geq 0, \lambda} \int_{-\infty}^{\infty}\left[\left(\delta t k+\theta x k-0.5 k^{2}-0.5 \gamma x^{2}\right) \frac{1}{\sigma} \phi\left(\frac{t-z}{\sigma}\right)-\frac{\delta \gamma x}{\theta}\left(1-\Phi\left(\frac{t-z}{\sigma}\right)\right)\right] d t \\
-\lambda\left[\gamma z-\int_{-\infty}^{\infty} \frac{\delta \gamma x}{\theta} \frac{1}{\sigma} \phi\left(\frac{t-z}{\sigma}\right) d t\right]-\bar{U} .
\end{aligned}
$$

${ }^{15}$ We will show below that the f.o.c of Eq. (9) has a unique solution. Note that the LHS of Eq. (9) is positive when $z$ is close to zero, and is negative when $z$ approaches infinity. Thus the objective function for the manager (the expression above Eq. (9) is pseudo-concave, and the solution to Eq. (9) is the optimal solution. 
Since Program L allows only a subset of mechanisms of Program P, it must be that $E \Pi^{L} \leq E \Pi^{P}$. However, comparing Eqs. (10) and (13) shows that $E \Pi^{L}=E \Pi^{R} \geq E \Pi^{P}$. Therefore, $E \Pi^{L}=E \Pi^{P}=E \Pi^{R}$; so the optimal mechanism with linear compensation contracts cannot be further improved upon.

Optimal Mechanism: We now solve the optimal mechanism. To simplify notation, we scale down $t$ by $\sigma$ so that the new state variable $\left(t_{n}=t / \sigma\right)$ has a normal distribution with mean $z_{n}=z / \sigma$ and variance 1 . We also denote $\lambda_{n}=\lambda / \sigma$. Using these variable transformations to rewrite the objective function (Eq. 13), we have

$$
\begin{gathered}
E \Pi=\max _{k\left(t_{n}\right), x\left(t_{n}\right), z_{n} \geq 0, \lambda} \int_{-\infty}^{\infty}\left[\left(\delta t k+\theta x k-0.5 k^{2}-0.5 \gamma x^{2}\right) \phi\left(t_{n}-z_{n}\right)-\frac{\sigma \delta \gamma x}{\theta}\left(1-\Phi\left(t_{n}-z_{n}\right)\right)\right] d t_{n} \\
-\lambda\left[\gamma z-\int_{-\infty}^{\infty} \frac{\delta \gamma x}{\theta} \phi\left(t_{n}-z_{n}\right) d t_{n}\right]-\bar{U} .
\end{gathered}
$$

The f.o.c.s for interior solutions are

$$
\begin{aligned}
0= & \delta t+\theta x-k \\
0= & \theta k-\gamma x-\frac{\sigma \delta \gamma}{\theta} \mu\left(t_{n}-z_{n}\right)+\lambda \frac{\delta \gamma}{\theta} \\
0= & \int_{-\infty}^{\infty}\left[\left(\delta t k+\theta x k-0.5 k^{2}-0.5 \gamma x^{2}\right)\left(t_{n}-z_{n}\right)-\frac{\sigma \delta \gamma x}{\theta}\right] \phi\left(t_{n}-z_{n}\right) d t_{n} \\
& -\lambda\left[\sigma \gamma-\int_{-\infty}^{\infty} \frac{\delta \gamma x}{\theta}\left(t_{n}-z_{n}\right) \phi\left(t_{n}-z_{n}\right) d t_{n}\right] \\
0 & \int_{-\infty}^{\infty} \frac{\delta \gamma x}{\theta} \phi\left(t_{n}-z_{n}\right) d t_{n}-\gamma z
\end{aligned}
$$

where the third equation uses the fact that $\phi^{\prime}(y)=-y \phi(y)$.

Define $t_{n}^{*}$ such that

$$
t_{n}^{*}+\frac{\gamma}{\theta^{2}}\left(\lambda_{n}-\mu\left(t_{n}^{*}-z_{n}\right)\right)=0
$$

It can be shown that $t_{n}^{*} \geq 0$ (Lemma 1). For $t_{n} \geq t_{n}^{*}$, the first two f.o.c.s (with respect to $k$ and $x$ ) imply that

$$
\begin{aligned}
k^{*}\left(t_{n}\right) & =\frac{\sigma \gamma \delta}{\gamma-\theta^{2}}\left[t_{n}+\lambda_{n}-\mu\left(t_{n}-z_{n}\right)\right] \\
x^{*}\left(t_{n}\right) & =\frac{\sigma \theta \delta}{\gamma-\theta^{2}}\left[t_{n}+\frac{\gamma}{\theta^{2}}\left(\lambda_{n}-\mu\left(t_{n}-z_{n}\right)\right)\right]
\end{aligned}
$$

for $t_{n}<t_{n}^{*}$, then $x^{*}=0$ and $k^{*}=\max (0, \delta t)$.

Substituting $k^{*}$ and $x^{*}$ into the fourth f.o.c. (with respect to $\lambda$ ) yields

$$
0=\frac{\sigma \delta^{2}}{\gamma-\theta^{2}} \int_{t_{n}^{*}}^{\infty}\left[t_{n}+\frac{\gamma}{\theta^{2}}\left(\lambda_{n}-\mu\left(t_{n}-z_{n}\right)\right)\right] \phi\left(t_{n}-z_{n}\right) d t_{n}-\sigma z_{n} .
$$


Using the facts that (i) $1-\Phi(y)=\Phi(-y)$; (ii) $\int y \phi(y) d y=-\int d \phi(y)=-\phi(y)$; and (iii) $\int(1-\Phi(y)) d y=$ $y(1-\Phi(y))+\int y \phi(y) d y=y \Phi(-y)-\phi(y)$, we can rewrite the above equation as

$$
\begin{aligned}
z_{n} & =\frac{\delta^{2}}{\gamma-\theta^{2}}\left[\phi\left(t_{n}^{*}-z_{n}\right)+\left(z_{n}+\frac{\lambda_{n} \gamma}{\theta^{2}}\right) \Phi\left(z_{n}-t_{n}^{*}\right)+\frac{\gamma}{\theta^{2}}\left[\left(t_{n}^{*}-z_{n}\right) \Phi\left(z_{n}-t_{n}^{*}\right)-\phi\left(t_{n}^{*}-z_{n}\right)\right]\right] \\
& =\frac{\delta^{2}}{\theta^{2}}\left[\frac{\gamma}{\gamma-\theta^{2}}\left(t_{n}^{*}+\lambda_{n}\right) \Phi\left(z_{n}-t_{n}^{*}\right)-\left[\phi\left(z_{n}-t_{n}^{*}\right)+z_{n} \Phi\left(z_{n}-t_{n}^{*}\right)\right]\right] .
\end{aligned}
$$

Substituting the optimal $x^{*}$ and $k^{*}$ into the third f.o.c (with respect to $z_{n}$ ) yields

$$
\begin{aligned}
0= & -\int_{0}^{\infty}\left[0.5\left(k^{* 2}-\gamma x^{* 2}\right) d \phi\left(t_{n}-z_{n}\right)+\frac{\delta \sigma \gamma x^{*}}{\theta} \phi\left(t_{n}-z_{n}\right) d t_{n}\right]-\lambda\left[\gamma \sigma+\frac{\delta \gamma}{\theta} \int_{t_{n}^{*}}^{\infty} x^{*} d \phi\left(t_{n}-z_{n}\right)\right] \\
= & \int_{0}^{\infty}\left(k^{*} k^{* \prime}-\gamma x^{*} x^{* \prime}-\frac{\delta \sigma \gamma x^{*}}{\theta}\right) \phi\left(t_{n}-z_{n}\right) d t_{n}-\lambda\left[\gamma \sigma+\frac{\delta \gamma}{\theta} \int_{t_{n}^{*}}^{\infty} x^{*} d \phi\left(t_{n}-z_{n}\right)\right] \\
= & \int_{t_{n}^{*}}^{\infty}\left(k^{*} k^{* \prime}-\gamma x^{*} x^{* \prime}-\frac{\delta \sigma \gamma x^{*}}{\theta}\right) \phi\left(t_{n}-z_{n}\right) d t_{n}+\delta^{2} \sigma^{2} \int_{0}^{t_{n}^{*}} t_{n} \phi\left(t_{n}-z_{n}\right) d t_{n} \\
& -\lambda\left[\gamma \sigma+\frac{\delta \gamma}{\theta} \int_{t_{n}^{*}}^{\infty} x^{*} d \phi\left(t_{n}-z_{n}\right)\right] .
\end{aligned}
$$

Using the shortcut notation $\mu=\mu\left(t_{n}-z_{n}\right)$, we can show that, for $t_{n} \geq t_{n}^{*}$,

$$
k^{*} k^{* \prime}-\gamma x^{*} x^{* \prime}-\frac{\delta \sigma \gamma x^{*}}{\theta}=\frac{\gamma^{2} \sigma^{2} \delta^{2}}{\theta^{2}\left(\gamma-\theta^{2}\right)}\left(\lambda_{n}-\mu\right)\left(\mu^{\prime}-1\right) .
$$

Plugging this back into the f.o.c. with respect to $z_{n}$ gives

$$
\begin{aligned}
0= & \frac{\gamma^{2} \sigma^{2} \delta^{2}}{\theta^{2}\left(\gamma-\theta^{2}\right)} \int_{t_{n}^{*}}^{\infty}\left(\lambda_{n}-\mu\right)\left(\mu^{\prime}-1\right) \phi\left(t_{n}-z_{n}\right) d t_{n}-\frac{\lambda \delta \gamma}{\theta} \int_{t_{n}^{*}}^{\infty} x^{*} d \phi\left(t_{n}-z_{n}\right) \\
& +\delta^{2} \sigma^{2}\left[\int_{0}^{t_{n}^{*}} z_{n} d \Phi\left(t_{n}-z_{n}\right)-\int_{0}^{t_{n}^{*}} d \phi\left(t_{n}-z_{n}\right)\right]-\lambda \gamma \sigma \\
= & \frac{\gamma^{2} \sigma^{2} \delta^{2}}{\theta^{2}\left(\gamma-\theta^{2}\right)} \int_{t_{n}^{*}}^{\infty}\left[-\lambda_{n} \frac{\gamma-\theta^{2}}{\gamma}-\mu \mu^{\prime}+\mu\right] \phi\left(t_{n}-z_{n}\right) d t_{n} \\
& +\delta^{2} \sigma^{2}\left[z_{n}\left(\Phi\left(t_{n}^{*}-z_{n}\right)-\Phi\left(-z_{n}\right)\right)-\phi\left(t_{n}^{*}-z_{n}\right)+\phi\left(-z_{n}\right)\right]-\lambda \gamma \sigma \\
= & -\frac{\lambda_{n} \gamma \sigma^{2} \delta^{2}}{\theta^{2}} \Phi\left(z_{n}-t_{n}^{*}\right)-\frac{\gamma^{2} \sigma^{2} \delta^{2}}{\theta^{2}\left(\gamma-\theta^{2}\right)}\left[\int_{t_{n}^{*}}^{\infty}\left(1-\Phi\left(t_{n}-z_{n}\right)\right) d \mu-\int_{t_{n}^{*}}^{\infty} \mu \phi\left(t_{n}-z_{n}\right) d t_{n}\right] \\
& +\delta^{2} \sigma^{2}\left[z_{n}\left(\Phi\left(z_{n}\right)-\Phi\left(z_{n}-t_{n}^{*}\right)\right)-\phi\left(z_{n}-t_{n}^{*}\right)+\phi\left(z_{n}\right)\right]-\lambda \gamma \sigma \\
= & -\frac{\lambda_{n} \gamma \sigma^{2} \delta^{2}}{\theta^{2}} \Phi\left(z_{n}-t_{n}^{*}\right)+\frac{\gamma^{2} \sigma^{2} \delta^{2}}{\theta^{2}\left(\gamma-\theta^{2}\right)}\left(1-\Phi\left(t_{n}^{*}-z_{n}\right)\right) \mu\left(t_{n}^{*}-z_{n}\right) \\
& +\delta^{2} \sigma^{2}\left[z_{n}\left(\Phi\left(z_{n}\right)-\Phi\left(z_{n}-t_{n}^{*}\right)\right)-\phi\left(z_{n}-t_{n}^{*}\right)+\phi\left(z_{n}\right)\right]-\lambda \gamma \sigma .
\end{aligned}
$$

By the definition of $t_{n}^{*}, \mu\left(t_{n}^{*}-z_{n}\right)=\theta^{2} t_{n}^{*} / \gamma+\lambda_{n}$. So we continue with

$$
0=-\frac{\lambda_{n} \gamma \sigma^{2} \delta^{2}}{\theta^{2}} \Phi\left(z_{n}-t_{n}^{*}\right)+\frac{\gamma \sigma^{2} \delta^{2}}{\gamma-\theta^{2}} \Phi\left(z_{n}-t_{n}^{*}\right) t_{n}^{*}+\frac{\lambda_{n} \gamma^{2} \sigma^{2} \delta^{2}}{\theta^{2}\left(\gamma-\theta^{2}\right)} \Phi\left(z_{n}-t_{n}^{*}\right)
$$




$$
\begin{aligned}
& +\delta^{2} \sigma^{2}\left[-\left[\phi\left(z_{n}-t_{n}^{*}\right)+z_{n} \Phi\left(z_{n}-t_{n}^{*}\right)\right]+\left[\phi\left(z_{n}\right)+z_{n} \Phi\left(z_{n}\right)\right]\right]-\lambda \gamma \sigma \\
= & \delta^{2} \sigma^{2}\left[\frac{\gamma}{\gamma-\theta^{2}}\left(t_{n}^{*}+\lambda_{n}\right) \Phi\left(z_{n}-t_{n}^{*}\right)-\left[\phi\left(z_{n}-t_{n}^{*}\right)+z_{n} \Phi\left(z_{n}-t_{n}^{*}\right)\right]+\left[\phi\left(z_{n}\right)+z_{n} \Phi\left(z_{n}\right)\right]\right]-\lambda \gamma \sigma .
\end{aligned}
$$

From Eq. (15), the above equation can be simplified as

$$
\begin{aligned}
0 & =\delta^{2} \sigma^{2}\left[\frac{\theta^{2}}{\delta^{2}} z_{n}+\left[\phi\left(z_{n}\right)+z_{n} \Phi\left(z_{n}\right)\right]\right]-\lambda \gamma \sigma, \\
\lambda_{n} & =\frac{\delta^{2}}{\gamma}\left[\phi\left(z_{n}\right)+z_{n} \Phi\left(z_{n}\right)\right]+\frac{\theta^{2}}{\gamma} z_{n} .
\end{aligned}
$$

Eqs. (14)-(16) define the solution to the mechanism design problem, $\left(\lambda_{n}^{*}, z_{n}^{*}, t_{n}^{*}\right)$, which are identical to Eqs. (1)-(3). Lemma 1 shows that there is a unique and positive solution $\left(\lambda_{n}^{*}, z_{n}^{*}, t_{n}^{*}\right)$.

From such a solution, we have $z^{*}=\sigma z_{n}^{*}, t^{*}=\sigma t_{n}^{*}$ and $\lambda^{*}=\sigma \lambda_{n}^{*}$. For $t<t^{*}, k^{*}(t)=\max (0, \delta t)$ and $x^{*}(t)=b^{*}(t)=0 ;$ for $t \geq t^{*}=\sigma t_{n}^{*}$, we have

$$
\begin{aligned}
k^{*}(t) & =\frac{\gamma \delta}{\gamma-\theta^{2}}\left[t+\sigma\left(\lambda_{n}^{*}-\mu\left(t / \sigma-z_{n}^{*}\right)\right)\right], \\
x^{*}(t) & =\frac{\theta \delta}{\gamma-\theta^{2}}\left[t+\frac{\sigma \gamma}{\theta^{2}}\left(\lambda_{n}^{*}-\mu\left(t / \sigma-z_{n}^{*}\right)\right)\right]
\end{aligned}
$$

and

$$
b^{*}(t)=\frac{\gamma x^{*}(t)}{\theta k^{*}(t)}=1+\left(\frac{\gamma}{\theta^{2}}-1\right) \frac{\lambda_{n}^{*}-\mu\left(t / \sigma-z_{n}^{*}\right)}{t / \sigma+\lambda_{n}^{*}-\mu\left(t / \sigma-z_{n}^{*}\right)}
$$

The salary is

$$
\begin{aligned}
a^{*}(t) & =U(t)+0.5 \gamma x^{*}(t)^{2}-b^{*}(t)\left[\left(\delta t+\theta x^{*}(t)\right) k^{*}(t)-0.5 k^{*}(t)^{2}\right] \\
& =\bar{U}+\int_{-\infty}^{t} \delta b^{*}(s) k(s) d s+0.5 \gamma x^{*}(t)^{2}-b^{*}(t)\left[\left(\delta t+\theta x^{*}(t)\right) k^{*}(t)-0.5 k^{*}(t)^{2}\right] \\
& =\bar{U}+\int_{-\infty}^{t} \delta b^{*}(s) k(s) d s-\delta b^{*}(t) k^{*}(t) t+0.5 b^{*}(t) k^{*}(t)^{2}\left[1-\theta^{2} b^{*}(t) / \gamma\right],
\end{aligned}
$$

where the last equality follows from $x^{*}(t)=\theta b^{*}(t) k^{*}(t) / \gamma$.

It is straightforward to verify that $x^{*}(t)$ is increasing in $t$ (since $\mu^{\prime}<0$ ). By standard arguments (Mirrlees, 1971), the (IC2) constraint is satisfied.

Q.E.D.

Proof of Corollary 1. (i) Note

$$
b^{*}(t)-1=\left(\frac{\gamma}{\theta^{2}}-1\right) \frac{\lambda_{n}^{*}-\mu\left(t / \sigma-z_{n}^{*}\right)}{t / \sigma+\lambda_{n}^{*}-\mu\left(t / \sigma-z_{n}^{*}\right)} .
$$

From $\lim _{y \rightarrow \infty} \mu(y)=0$, for sufficiently high $t$, the nominator approaches to $\lambda_{n}^{*}$ which is positive from Lemma 1; the denominator is positive. Therefore, $b^{*}(t)>1$ for high $t$. 
(ii) Taking derivative yields

$$
\frac{d b^{*}(t)}{d t}=-\left(\frac{\gamma}{\theta^{2}}-1\right) \frac{\mu^{\prime}\left(t / \sigma-z_{n}^{*}\right) t / \sigma+\lambda_{n}^{*}-\mu\left(t / \sigma-z_{n}^{*}\right)}{\sigma\left[t / \sigma+\lambda_{n}^{*}-\mu\left(t / \sigma-z_{n}^{*}\right)\right]^{2}} .
$$

Define a function according to the nominator:

$$
M(t)=\lambda_{n}^{*}-\mu\left(t / \sigma-z_{n}^{*}\right)+\mu^{\prime}\left(t / \sigma-z_{n}^{*}\right) t / \sigma .
$$

Note

$$
\begin{aligned}
\frac{d M}{d t} & =\frac{t}{\sigma^{2}} \mu^{\prime \prime}\left(\frac{t}{\sigma}-z_{n}^{*}\right)>0, \\
M\left(t^{*}\right) & =\lambda_{n}^{*}-\mu\left(t_{n}^{*}-z_{n}^{*}\right)+t_{n}^{*} \mu^{\prime}\left(t_{n}^{*}-z_{n}^{*}\right)=-\frac{\theta^{2}}{\gamma} t_{n}^{*}+t_{n}^{*} \mu^{\prime}\left(t_{n}^{*}-z_{n}^{*}\right)<0, \\
M(\infty) & =\lim _{t \rightarrow \infty}\left[\lambda_{n}^{*}-\mu\left(\frac{t}{\sigma}-z_{n}^{*}\right)+z_{n}^{*} \mu^{\prime}\left(\frac{t}{\sigma}-z_{n}^{*}\right)+\left(\frac{t}{\sigma}-z_{n}^{*}\right) \mu^{\prime}\left(\frac{t}{\sigma}-z_{n}^{*}\right)\right] \\
& =\lambda_{n}^{*}-\lim _{y \rightarrow \infty} \mu(y)+z_{n}^{*} \lim _{y \rightarrow \infty} \mu^{\prime}(y)+\lim _{y \rightarrow \infty} y \mu^{\prime}(y) \\
& =\lambda_{n}^{*}>0,
\end{aligned}
$$

where the first inequality follows from $\mu^{\prime \prime}>0$, the second equation obtains by plugging in the expression of $t_{n}^{*}$ in Eq. (2), and the last inequality obtains by using the facts $\lim _{y \rightarrow \infty} \mu(y)=\lim _{y \rightarrow \infty} \mu^{\prime}(y)=$ $\lim _{y \rightarrow \infty} y \mu^{\prime}(y)$. Therefore, $M(t)=0$ has a unique and positive solution denoted $t_{1}$ with $t_{1}>t^{*} ; M(t)>0$ if $t>t_{1}$, and $M(t)<0$ if $t_{1}<t_{1}$. The derivative $d b^{*}(t) / d t$ is positive (negative) for $t<t_{1}\left(t>t_{1}\right)$.

(iii) The monotonicity of $k^{*}(t)$ and $x^{*}(t)$ follows immediately from $\mu^{\prime}<0$.

(iv) Define $\bar{t}$ such that $\lambda_{n}^{*}-\mu\left(\bar{t} / \sigma-z_{n}^{*}\right)=0$. Note

$$
\lambda_{n}^{*}-\mu\left(\bar{t} / \sigma-z_{n}^{*}\right)=0>-\theta^{2} t_{n}^{*} / \gamma=\lambda_{n}^{*}-\mu\left(t_{n}^{*}-z_{n}^{*}\right) .
$$

From $\mu^{\prime}<0$, it must be $\bar{t}>\sigma t_{n}^{*}=t^{*}$. Since $k^{*}(\bar{t})-k^{f b}(\bar{t})=0$ and

$$
k^{*}(t)-k^{f b}(t)=\frac{\sigma \gamma \delta}{\gamma-\theta^{2}}\left(\lambda_{n}^{*}-\mu\left(t / \sigma-z_{n}^{*}\right)\right)
$$

increases in $t$, it must be $k^{*}(t)>k^{f b}(t)$ if and only if $t>\bar{t}$. Similarly, we obtain the result for $x^{*}(t)$.

Q.E.D.

Proof of Corollary 2. (i) To save space, we just prove the monotonicity of $b^{*}$; those of $x^{*}$ and $k^{*}$ can be derived almost identically.

For $t \leq t^{*}$, it is obvious $\partial b / \partial \sigma=0$. For $t>t^{*}$, we have

$$
\frac{\partial b^{*}}{\partial \sigma}=\frac{t}{\sigma^{2}}\left(\frac{\gamma}{\theta^{2}}-1\right) \frac{\lambda_{n}^{*}-\mu\left(t / \sigma-z_{n}^{*}\right)+\mu^{\prime}\left(t / \sigma-z_{n}^{*}\right) t / \sigma}{\left[t / \sigma+\lambda_{n}^{*}-\mu\left(t / \sigma-z_{n}^{*}\right)\right]^{2}} .
$$


Similar to the proof of Corollary $1, \partial b^{*} / \partial \sigma$ is positive for $t>t_{1}$ and negative for $t<t_{1}$.

(ii) Note $z^{*}=\sigma z_{n}^{*}$ where $z_{n}^{*}$ is positive and independent of $\sigma$; therefore, $z^{*}$ increases in $\sigma$. $\quad$ Q.E.D.

Proof of Corollary 3. (i) Lemma 1 shows that $z_{n}^{*}$ increases (decreases) in $\delta$ and $\theta(\gamma)$. Since $z^{*}=\sigma z_{n}^{*}$, the same holds for $z^{*}$.

(ii) Note

$$
\begin{aligned}
\lim _{t \rightarrow \infty} \frac{\partial\left(k^{*}-k^{f b}\right)}{\partial \delta} & =\lim _{t \rightarrow \infty} \frac{\gamma \sigma}{\gamma-\theta^{2}}\left[\lambda_{n}^{*}-\mu\left(\frac{t}{\sigma}-z_{n}^{*}\right)+\delta\left(\frac{d \lambda_{n}^{*}}{d \delta}+\mu^{\prime}\left(\frac{t}{\sigma}-z_{n}^{*}\right) \frac{d z_{n}^{*}}{d \delta}\right)\right] \\
& =\frac{\gamma \sigma}{\gamma-\theta^{2}}\left(\lambda_{n}^{*}+\delta \frac{d \lambda_{n}^{*}}{d \delta}\right)>0,
\end{aligned}
$$

from Lemma 1. Therefore, when $t$ is sufficiently high, $k^{*}(t)-k^{f b}(t)$ increases in $\delta$; similarly, $k^{*}(t)-k^{f b}(t)$ increases in $\theta$ and decreases in $\gamma$. The results about overinvestment in managerial effort can be obtained similarly.

Q.E.D. 


\section{References}

[1] Antle, R., and G.D. Eppen, 1985, Capital rationing and organizational slack in capital budgeting, Management Science 31, 163-174.

[2] Berkovitch, E., and R. Israel, 2004, Why the NPV criterion does not maximize NPV, Review of Financial Studies 17, 239-255.

[3] Bernardo, A.E., H. Cai, and J. Luo, 2001, Capital budgeting and compensation with asymmetric information and moral hazard, Journal of Financial Economics 61, 311-344.

[4] Christensen, C.M., 1997, The Innovator's Dilemma: When New Technologies Cause Great Firms to Fail 1997, Harper Collins, NY.

[5] Gompers, P., 1995, Optimal investment, monitoring and the staging of venture capital, Journal of Finance 50, 1461-1489.

[6] Gompers, P., J. Lerner, and D.S. Scharfstein, 2005, Entrepreneurial spawning: Public corporations and the genesis of new ventures, 1986 to 1999, Journal of Finance 60, 577-614.

[7] Gromb, D., and D. Scharfstein, 2005, Entrepreneurship in equilibrium, working paper, NBER.

[8] Harris, M., and A. Raviv, 1996, The capital budgeting process: Incentives and information, Journal of Finance 51, 1139-1174.

[9] Hellmann, T., 1998, The allocation of control rights in venture capital contracts, Rand Journal of Economics 29, 57-76.

[10] Hellmann, T., and M. Puri, 2000, The interaction between product market and financing strategy: The role of venture capital, Review of Financial Studies 13, 959-984.

[11] Henderson, R., 1993, Underinvestment and incompetence as responses to radical innovation: Evidence from the photolithographic alignment equipment industry, Rand Journal of Economics 24, 248-270.

[12] Holmstrom, B., 1979, Moral hazard and observability, Bell Journal of Economics, 10:74-91

[13] Holmstrom, B., and P. Milgrom, 1987, Aggregation and linearity in the provision of intertemporal incentives, Econometrica 55, 597-619.

[14] Jovanovic, B., 1979, Job matching and the theory of turnover, Journal of Political Economy 87, 972-990.

[15] Kaplan, S. N., and Per Strömberg, 2003, Financial contracting meets the real world: An empirical analysis of venture capital contracts, Review of Economic Studies 70, 281-315. 
[16] Laffont, J.-J., and J. Tirole, 1986, Using cost observation to regulate firms, Journal of Political Economy 94, 614-641.

[17] Lewis, T.R., and D.E.M. Sappington, 1997, Information management in incentive problems, Journal of Political Economy 105, 796-821.

[18] Milgrom, P., and J. Roberts, 1992, Economics, Organizations and Management, Prentice Hall, Englewood Cliffs.

[19] Mirrlees, J.A., 1971, An exploration in the theory of optimum income taxation, Review of Economic Studies 38, 135-208

[20] Prendergast, C., 1999, The provision of incentives in firms, Journal of Economic Literature 37, 7-63.

[21] Prendergast, C., 2002, The tenuous trade-off of risk and incentives, Journal of Political Economy 104, 1105-1134.

[22] Rajan, R., H. Servaes, and L. Zingales, 2000, The Costs of diversity: The diversification discount and inefficient investment, Journal of Finance 55, 35-80.

[23] Rosen, S., 1982, Authority, control, and the distribution of earnings, Bell Journal of Economics 13, 311-321.

[24] Scharfstein, D.S., and J.C. Stein, 2000, The dark side of internal capital markets: Divisional rentseeking and inefficient investment, Journal of Finance 55, 2537-2564.

[25] Shi, L., 2003, Respondable risk and incentives: Evidence from executive compensation, working paper, University of Chicago.

[26] Stein, J.C., 1997, Internal capital markets and the competition for corporate resources, Journal of Finance 52, 111-133.

[27] Szalay, D., 2003, Procurement with an endogenous type distribution, working paper, HEC. 